\section{Commentary: Until the ideal aortic valve prosthesis is invented, pick your poison!}

\author{
Rachel Eikelboom, MD, and \\ Michael H. Yamashita, MDCM, MPH
}

Aortic valve replacement (AVR) is the only definitive treatment for severe aortic valve disease and approximately 100,000 AVRs are performed each year in North America. ${ }^{1}$ Choice of aortic valve prosthesis involves weighing the risks of bioprosthetic structural valve deterioration (SVD) and surgical reintervention against the risks of mechanical valve thrombosis and lifelong anticoagulation. The impact of prosthesis choice on long-term survival is incompletely understood, and the large propensity-matched retrospective study from Attia and colleagues ${ }^{2}$ in this edition of the Journal provides illuminating insights.

Attia and colleagues ${ }^{2}$ compare perioperative, reoperative, and long-term outcomes in 6143 patients undergoing isolated bioprosthetic or mechanical AVR at the Cleveland Clinic between 1990 and 2020. Perioperative morbidity and mortality were similar between groups. As expected, reoperation was more common in the bioprosthetic group with $16 \%$ requiring reoperation at 10 years compared with $5.5 \%$ in the mechanical group. Reoperation rates increased sharply after 10 years in the bioprosthetic group, exceeding $30 \%$ at 14 years. Reoperation was not associated with excess mortality among 527 propensity-matched pairs, which highlights the expertise of the Cleveland Clinic but may not be generalizable to smaller centers with lower volumes. Furthermore, reoperative mortality likely has been incompletely evaluated given that only $10 \%$ of the bioprosthetic group was followed to 14 years. Patients

From the Department of Surgery, Max Rady College of Medicine, University of Manitoba, Winnipeg, Manitoba, Canada; and Cardiac Sciences Program, St Boniface Hospital, Winnipeg, Manitoba, Canada.

Disclosures: The authors reported no conflicts of interest.

The Journal policy requires editors and reviewers to disclose conflicts of interest and to decline handling or reviewing manuscripts for which they may have a conflict of interest. The editors and reviewers of this article have no conflicts of interest.

Received for publication Nov 21, 2020; revisions received Nov 21, 2020; accepted for publication Nov 23, 2020; available ahead of print Dec 3, 2020.

Address for reprints: Michael H. Yamashita, MDCM, MPH, Y3519 - 409 Tache Ave, Winnipeg, Manitoba, Canada R2H 2A6 (E-mail: myamashita@sbgh.mb.ca).

J Thorac Cardiovasc Surg 2022;164:1456-7

0022-5223/\$36.00

Copyright (c) 2020 by The American Association for Thoracic Surgery

https://doi.org/10.1016/j.jtcvs.2020.11.123

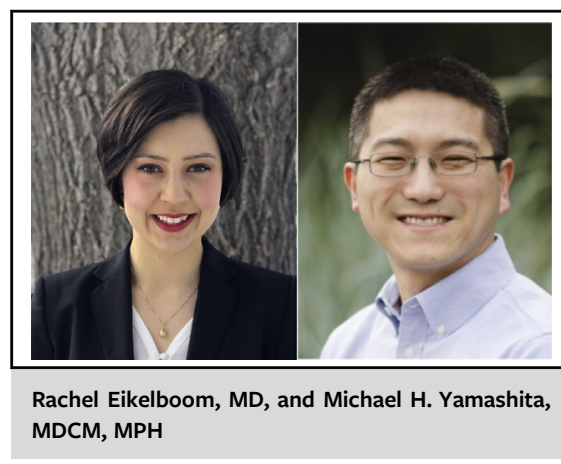

CENTRAL MESSAGE

Long-term survival after bio-

prosthetic or mechanical AVR

appears to be similar. Thus, valve

choice should be aligned with

patient preference rather than

age so long as safe redo AVR can

be offered.

requiring reoperation at longer intervals after their index procedure may have higher perioperative risk due to increased age. Overall, the authors found no difference in long-term risk-adjusted mortality between the bioprosthetic and mechanical valve groups.

The only randomized controlled trial to compare contemporary (ie, bileaflet) mechanical and bioprosthetic aortic valves found no difference in survival among 310 patients followed over a mean of 106 months. ${ }^{3}$ In contrast, Goldstone and colleagues ${ }^{4}$ retrospective database study of mortality after AVR in 9942 patients in California found increased 15 -year mortality in patients aged 45 to 54 years who received a bioprosthetic rather than a mechanical prosthesis. This increase appears to be driven by a $7.1 \%$ 30-day mortality after redo AVR, which when compared with the 2.5\% 30-day reoperative mortality reported by the Cleveland Clinic $^{5}$ highlights the importance of safe reoperative surgery given the known risks of SVD after bioprosthetic AVR.

The ultimate goal in the management of aortic valve disease is to develop a durable AVR that does not trigger thrombosis, thus reducing or eliminating the risks of reoperation, stroke, and anticoagulation-related bleeding. In the meantime, patients with bioprosthetic SVD can now undergo low-risk reintervention with valve-in-valve transcatheter aortic valve replacement, although long-term outcomes remain to be seen. For patients with mechanical valves, research on safer anticoagulation includes lower 
international normalized ratio targets ${ }^{6}$ and alternative anticoagulants such as the factor Xa inhibitor apixaban ${ }^{7}$ or the novel oral factor XIa inhibitors. ${ }^{8}$ Until the ideal valve is available, one that has lifelong durability with no requirement for anticoagulation, or improved management of current valves is demonstrated in high-quality randomized trials, both bioprosthetic and mechanical AVR are reasonable options and patient preference should guide choice of prosthesis.

\section{References}

1. D'Agostino RS, Jacobs JP, Badhwar V, Fernandez FG, Paone G, Wormuth DW, et al. The Society of Thoracic Surgeons adult cardiac surgery database: 2019 update on outcomes and quality. Ann Thorac Surg. 2019;107:24-32.

2. Attia T, Yang Y, Svensson LG, Toth AJ, Rajeswaran J, Blackstone EH. Similar long-term survival after isolated bioprosthetic versus mechanical aortic valve replacement: a propensity-matched analysis. J Thorac Cardiovasc Surg. 2022; 164:1444-55.e4
3. Stassano P, Di Tommaso L, Monaco M, Iorio F, Pepino P, Spampinato N, et al Aortic valve replacement: a prospective randomized evaluation of mechanical versus biological valves in patients ages 55 to 70 years. J Am Coll Cardiol. 2009;54:1862-8.

4. Goldstone AB, Chiu P, Baiocchi M, Lingala B, Patrick WL, Fischbein MP, et al Mechanical or biologic prostheses for aortic-valve and mitral-valve replacement. N Engl J Med. 2017;377:1847-57.

5. Naji P, Griffin BP, Sabik JF, Kusunose K, Asfahan F, Popovic ZB, et al. Characteristics and outcomes of patients with severe bioprosthetic aortic valve stenosis undergoing redo surgical aortic valve replacement. Circulation. 2015;132: 1953-60.

6. Belley-Cote E, Whitlock R. LIMIT: lower INR to minimise bleeding with mechanical valves. Available at: https://www.phri.ca/research/limit/. Accessed November 19, 2020

7. Jawitz OK, Wang TY, Lopes RD, Chavez A, Boyer B, Kim H, et al. Rationale and design of PROACT Xa: a randomized, multicenter, open-label, clinical trial to evaluate the efficacy and safety of apixaban versus warfarin in patients with a mechanical on-X aortic heart valve. Am Heart J. 2020;227: 91-9.

8. Jaffer IH, Stafford AR, Fredenburgh JC, Whitlock RP, Chan NC, Weitz JI. Dabigatran is less effective than warfarin at attenuating mechanical heart valve-induced thrombin generation. J Am Heart Assoc. 2015;4:e002322. 